\title{
Incidence of resistant mastitis in dairy cows in Tamil Nadu, India
}

\author{
D. Chandrasekaran ${ }^{1 *}$, A. P. Nambi1 ${ }^{1}$, P. S. Thirunavukkarasu ${ }^{1}$, P. Venkatesan ${ }^{2}$, K. G. Tirumurugaan ${ }^{2}$ \\ and $\mathrm{S}$. Vairamuthu ${ }^{3}$ \\ *1 Department of Veterinary Clinical Medicine, Ethics and Jurisprudence, Madras Veterinary College, Tamil Nadu \\ Veterinary and Animal Sciences University, Chennai 600 007(Tamil Nadu), INDIA. \\ ${ }^{2}$ Centralized Clinical Laboratory, Madras Veterinary College, Tamil Nadu Veterinary and Animal Sciences University, \\ Chennai 600007 (Tamil Nadu), INDIA. \\ ${ }^{3}$ Department of Animal Biotechnology, Madras Veterinary College, Tamil Nadu Veterinary and Animal Sciences \\ University, Chennai 600 007(Tamil Nadu), INDIA \\ Corresponding author. E-mail: drchandrus@yahoo.com
}

Received: November 19, 2014; Revised received: April 12, 2015; Accepted: April 20, 2015

Abstract: The incidence of resistant mastitis in dairy cows in Tamil Nadu, India was $56.1 \%$. The predominant resistant causative pathogen was Escherichia coli $(50.64 \%)$ followed by Staphylococcus aureus $(44.25 \%)$ and Methicillin resistant Staphylococcus aureus (5.11\%). Incidence of resistant mastitis was high in Holstein Friesian cross breed followed by Jersey cross breed and non descript. Highest incidence was observed in early stage of third lactation. In vitro antibiotic sensitivity test revealed the E. coli, S. aureus and MRSA organisms showed more sensitivity to enrofloxacin, amoxicillin +sulbactam, gentamicin and ceftriaxone and had highest resistant to penicillin followed by amoxicillin, oxytetracycline and methicillin. The study highlights the need for preventing the indiscriminate use of antibiotics.

Keywords: Escherichia coli, Methicillin resistant Staphylococcus aureus

\section{INTRODUCTION}

Mastitis is considered as most important disease affecting the productive performance of cattle world-wide contributing to the economic losses (Kumar et al., 2010). Due to the involvement of multiple aetiological agents it always remains as a challenge to veterinarians all over the globe. Staphylococcus aureus and Escherichia coli are the most frequent causes of contagious and environmental clinical mastitis in dairy cattle, respectively (Olde Riekerink et al., 2008). Antimicrobial therapy is commonly implemented for mastitis prevention and control. Unfortunately, despite the best possible antimicrobial treatments, failures of bacteriological cure are common, especially for $S$. aureus mastitis and antimicrobial resistance (AMR) which is considered one of the reasons for low cure rates (Barkema et al., 2006). Additionally, AMR in bacteria is a public health hazard, and antimicrobial use is considered a potentially important driver of AMR. Acquired antimicrobial resistance in bacteria is an increasing threat in human as well as in veterinary medicine. The emergence of antibiotic-resistance in $S$. aureus mastitic dairy animals has been shown in recent years. Strains of $S$. aureus are reported to show resistance against multiple antimicrobials. Among the various antibiotic-resistant isolates, methicillin-resistant $S$. aureus (MRSA) is a serious cause because of its public health significance (Juhasz-Kaszanyitzky et al., 2007). Beta-lactam antibiotics are frequently used in mastitis therapy and the resistance is due to the production of beta-lactamases and low affinity penicillin-binding protein, PBP2A (Olsen et al., 2006). As on date $\beta$ -lactamase resistant penicillins such as methicillin and oxacillin are not used in dairy cows except for cloxacillin that is used in products for intramammary administration (Turutoglu et al., 2006). Therefore, the present study was conducted to study the incidence of drug resistant mastitis in dairy cows from Tamil Nadu.

\section{MATERIALS AND METHODS}

Sampling: Four hundred and one milk samples were collected from acute mastitic cows from Large Animal Clinic Medicine Unit of Madras Veterinary College Teaching Hospital and six dairy farms in Coimbatore district. Clinical examination was carried out as described by Boddie (2000).The cows selected for the present study were subjected to detailed history. The relevant information of each animal with regard to the breed, age, lactation number and stage of lactation were recorded.

Bacterial culturing: The guidelines of National Mastitis Council (NMC) were followed for sample collection, transportation, culture and isolation of bacteria. Milk samples were inoculated into nutrient broth and streaked on to blood agar and Mac Conkey's agar plates and subsequently inoculated to specific media for pure culture of bacterial isolates. The bacteria grown on the 
plates were identified up to the genus level based on the culture characters, staining and biochemical reactions. The $S$. aureus isolates were also characterized by their growth on blood agar and mannitol salt agar, the positive results for catalase and coagulase while the E. coli isolates were identified on eosin methylene blue agar, a negative oxidase test.

Antibiotic sensitivity and resistance: The antimicrobial susceptibility of the different $E$. coli and $S$. aureus strains to the commonly used antibiotics were determined by agar disc diffusion on Muller-Hinton agar plates with 0.5 McFarland turbidity standards (CLSI, 2008). The Staphylococci isolates were confirmed to be MRSA by amplifying the MRSA specific genes mecA and blaZ as described by Lee (2003) and Martineau et al. (2000), respectively. Based on culture, isolation and sensitivity tests, cows with resistant mastitis were grouped as follows, Group I Escherichia coli $(\mathrm{n}=119)$, Group II Staphylococcus aureus $(\mathrm{n}=104)$ and Group III Methicillin resistant Staphylococcus aureus $(\mathrm{n}=12)$.

Statistical analysis: The results were statistically analyzed, utilizing SPSS - Version 14 statistical software package.

\section{RESULTS AND DISCUSSION}

Out of 401 dairy cows, resistant mastitis was detected in 235 cows accounting to $56.1 \%$ with the predominant resistant causative pathogen was E. coli $(50.64 \%)$ followed by $S$. aureus $(44.25 \%)$ and Methicillin resistant Staphylococcus aureus $(5.11 \%)$.

The antibiotic usage has directly contributed to an increased prevalence of resistance (DANMAP, 2001). All antimicrobial use in the herd may affect the resistance of $E$. coli isolates by increasing the presence of these antimicrobial agents in the cow's environment. Findings of above said studies are in partial agreement with the present study.

Sori et al. (2011) reported that $52.4 \%$ were resistant to 2 or $>2$ antimicrobial agents against $S$. aureus. $S$. aureus has developed multidrug resistance in many regions of the world (WHO, 2000), although reported prevalence rates indicated that wide variations existed regionally and even from herd to herd (Waage et al., 2002).

In the present study, prevalence of MRSA accounted for $5.11 \%$. However, we found nearly $10.34 \%$ of (12 out of 116) $S$. aureus strains to be MRSA. This was in agreement with Kumar et al., (2011) also reported MRSA prevalence of $13 \%$ of $S$. aureus isolates $(14 / 107)$ from cows with mastitis in a herd located in northwest India.

Breed wise, lactation wise, stage of lactation wise incidence of resistant mastitis in cows and antibiogram of the isolated bacterial pathogens are given in fig. 1, and tables 1-3, respectively.

Incidence of resistant mastitis was high in Holstein Friesian cross breed, followed by Jersey cross and non descript in E. coli and $S$. aureus group and Holstein Friesian cross breed and Jersey cross in MRSA group
(Fig. 1).

In the present study, incidence of E. coli, S. aureus and MRSA mastitis was high in Holstein Friesian cross breed followed by Jersey cross breed and non descript. Several authors reported that higher prevalence of mastitis in Holstein Friesian (Radostits et al., 2008 and Sharma and Maiti, 2010) (Fig. 1). These differences between breeds might be due to immune response to intra mammary infection between breeds (Sharma and Maiti, 2010).

Highest incidence was observed in third lactation followed by second, first, fourth, fifth lactation and least in sixth lactation in E. coli and $S$. aureus group and second lactation followed by third, fourth and first lactation in MRSA group (Table 1).

In the present study, it was found that the animals in the third lactation were affected more and it was highly significant when compared to other lactation period animals (Table 1). Various authors also recorded higher incidence during third lactation (Carlen et al., 2005 and Sachin Kumar, 2007). Higher incidence in third lactation could be attributed to the negative energy balance with concurrent fatty liver syndrome and oxidative stress may be correlated to production performance of the animal.

Highest incidence was observed in early stage of lactation followed by mid and late lactation in E. coli and S.aureus group and early stage of lactation followed by mid lactation in MRSA group (Table 2).

In the present study the incidence of mastitis was higher in early stage of lactation when compared to mid and late lactation (Table 2). This observation was in close agreement with Fadlemula et al. (2009) reported that the highest incidence of mastitis $(62.7 \%)$ was in the first month of lactation. Various workers also recorded higher incidence rate in early stage of lactation (Corbett, 2009 and Mohana Sundhari, 2010). Lairintluanga et al. (2003) and Sharma et al. (2011) opined that dairy cows seemed to have more oxidative stress and low antioxidants defence during early lactation and it could be due to stress of peak milk production during the early stage or just after parturition than in advanced pregnant cows.

Gowri (2010) recorded $11.5 \%$ of mastitis in periparturient cows with moderate and severe fatty liver and further suggested that increase in NEFA concentration might be attributed to impairment of immune system in fatty liver cows.

Antibiotic sensitivity and resistance: $E$. coli showed more sensitivity to enrofloxacin (79 \%) followed by amoxicillin and sulbactam (74\%), gentamicin (73.1\%) and ceftriaxone (69 \%). The isolates had highest resistance to penicillin (63 $\%$ ) followed by amoxicillin (52.1\%), oxytetracycline (47.9 $\%$ ) and methicillin (45.4\%) (Table 3).

Lehtolainen et al. (2003) recorded that $27 \%$ of E. coli isolates were resistant to one or more antimicrobial agents. Among resistant isolates highest resistance was against tetracycline, Dihydrostreptomycin (DHS) and 
Table 1. Lactation wise incidence of mastitis in cows.

\begin{tabular}{ccccc}
\hline Lactation & E. coli $(\mathbf{n = 1 1 9})$ & S. aureus $(\mathbf{n = 1 0 4})$ & MRSA $(\mathbf{n}=12)$ & $\chi^{2}$ test \\
\hline $1^{\text {st }}$ & $20.16 \%$ & $19.23 \%$ & $8.33 \%$ & \\
$2^{\text {nd }}$ & $31.93 \%$ & $28.84 \%$ & $41.66 \%$ & \\
$3^{\text {rd }}$ & $35.29 \%$ & $32.69 \%$ & $33.33 \%$ & 7.21 NS \\
$4^{\text {th }}$ & $5.88 \%$ & $13.46 \%$ & $16.66 \%$ & \\
$5^{\text {th }}$ & $5.04 \%$ & $2.88 \%$ & - & \\
$6^{\text {th }}$ & $1.68 \%$ & $2.88 \%$ & - & \\
\hline
\end{tabular}

NS - Non significant $(\mathrm{P}>0.05)$

Table 2. Stage of lactation wise incidence of mastitis in cows.

\begin{tabular}{|c|c|c|c|c|}
\hline Stage of Lactation & E. $\operatorname{coli}(\mathrm{n}=119)$ & S. aureus $(\mathrm{n}=104)$ & MRSA $(n=12)$ & $\chi^{2}$ test \\
\hline Early 1-3 Months & $63.9 \%$ & $69.2 \%$ & $83.3 \%$ & \\
\hline Mid 4-6 Months & $31.1 \%$ & $25 \%$ & $16.7 \%$ & \\
\hline Late 6-9 Months & $5 \%$ & $5.8 \%$ & - & $2.73^{\mathrm{NS}}$ \\
\hline
\end{tabular}

NS - Non significant $(\mathrm{P}>0.05)$

ampicillin and $41 \%$ were multiresistant. Multiresistant bacteria also tend to maintain their resistance to a particular antimicrobial even when that antimicrobial is absent from the environment if the other antimicrobials to which the resistance is linked are still present (Galland et al., 2001). The present observation was in agreement with Lairintluanga et al. (2003) and karthikeyan (2003) reported that gram negative pathogens were more sensitive to enrofloxacin and gentamicin and less sensitive to ampicillin and penicillin.

S. aureus isolates were most sensitive to enrofloxacin (79.8 $\%$ ) followed by gentamicin (71.2\%), amoxicillin and sulbactam $(69.2 \%)$ and ceftriaxone $(69.2 \%)$. The isolates showed highest resistance to penicillin $(63.5 \%)$ followed by amoxicillin (61.5\%), oxytetracycline (49\%) and methicillin (30.8\%) (Table 3).

The resistance of $S$. aureus to penicillin and ampicillin may be attributed to the production of betalactamase, an enzyme that inactivates penicillin and closely related antibiotics (Green and Bradely, 2004) and wide use of intramammary preparations containing combinations and broad-spectrum antibiotics (Pitkala et al., 2007). Edward et al. (2002) suggested a possible development of resistance from prolonged and indiscriminate usage of some antimicrobials. The present observation was in agreement with Lairintluanga et al. (2003) who reported that Staphylococcus Spp. was highly sensitive to enrofloxacin, gentamicin and least sensitive to ampicillin.

MRSA showed maximum sensitivity to enrofloxacin and amoxicillin and sulbactam (75\%) each, gentamicin (66.7 $\%)$ and ceftriaxone $(58.3 \%)$. The isolates showed highest resistance to methicillin (100\%), amoxicillin (91.7\%), followed by penicillin $(83.3 \%)$ and oxytetracycline $(41.7$ \%) (Table 3 ).

Table 3. In vitro antibiogram of isolated pathogens in cows.

\begin{tabular}{|c|c|c|c|c|c|c|}
\hline & \multicolumn{2}{|c|}{ E. coli $(n=119)$} & \multicolumn{2}{|c|}{ S. aureus $(\mathrm{n}=104)$} & \multicolumn{2}{|c|}{ MRSA (n=12) } \\
\hline & $\begin{array}{c}\text { Sensitive } \\
(\%)\end{array}$ & $\begin{array}{c}\text { Resistance } \\
(\%)\end{array}$ & $\begin{array}{c}\text { Sensitive } \\
(\%)\end{array}$ & $\begin{array}{c}\text { Resistance } \\
(\%)\end{array}$ & $\begin{array}{c}\text { Sensitive } \\
(\%)\end{array}$ & $\begin{array}{c}\text { Resistance } \\
(\%)\end{array}$ \\
\hline Enrofloxacin & 79 & 21 & 79.8 & 20.2 & 75 & 25 \\
\hline Amoxicillin + Sulbactam & 74 & 26 & 69.2 & 30.8 & 75 & 25 \\
\hline Gentamicin & 73.1 & 26.9 & 71.2 & 28.8 & 66.7 & 33.3 \\
\hline Ceftriaxone & 69 & 31 & 69.2 & 30.8 & 58.3 & 41.7 \\
\hline Oxytetracycline & 52.1 & 47.9 & 51 & 49 & 58.3 & 41.7 \\
\hline Methicillin & 54.6 & 45.4 & 47.1 & 52.9 & - & 100 \\
\hline Amoxicillin & 47.9 & 52.1 & 38.5 & 61.5 & 8.3 & 91.7 \\
\hline Penicillin G & 37 & 63 & 36.5 & 63.5 & 16.7 & 83.3 \\
\hline
\end{tabular}

MRSA- Methicillin resistant Staphylococcus aureus 


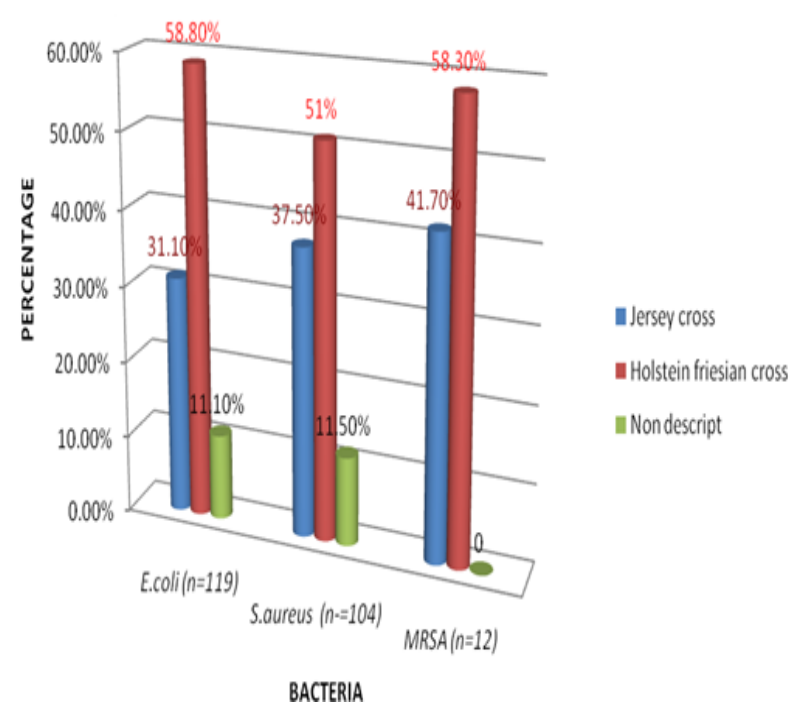

Fig. 1. Breed wise incidence of mastitis in cows.

Kumar et al.(2011) recorded a high prevalence of MRSA (13.1\%). The isolates were also highly resistant to streptomycin, oxytetracycline, gentamicin and chloramphenicol, pristinomycin and ciprofloxacin. The present observation was in agreement with Turutoglu et al. (2009) and Turkyılmaz et al. (2010). Kumar et al. (2010) reported that MRSA strains were multi-drug resistant which might be due to production of betalactamase and PBP2a (penicillin binding protein).

The incidence of MRSA mastitis by targeting specific gene mec A and blaZ in the study was 10.34 per cent (12/116). Loeffler and Lloyd (2010) opined that detection of mecA and blaZ gene by PCR was gold standard test for confirmation of methicillin resistance. This high incidence in the present study might be due to indiscriminate use of antibiotics and intramammary preparations used by the owner without the prescription of the veterinarian.

\section{Conclusion}

Incidence of resistant mastitis in dairy cows of Tamil Nadu, India was high. The predominant resistant causative pathogen was $E$. coli followed by $S$. aureus and MRSA. Incidence of resistant mastitis was high in Holstein Friesian cross breed in early stage of third lactation. Antimicrobial resistance to penicillin, amoxicillin, oxytetracycline and methicillin was found in clinical mastitis cases. It highlights the need for preventing the indiscriminate use of antibiotics.

\section{REFERENCES}

Barkema, H.W., Schukken, Y.H. and Zadoks, R.N. (2006). Invited review: The role of cow, pathogen, and treatment regimen in the therapeutic success of bovine Staphylococcus aureus mastitis. Journal of Dairy Science, 89: 1877-1895.

Boddie, G.F. (2000). Diagnostic method in Veterinary Medicine. Green world publishers, Lucknow.

Carlen, E., Schneider Mdel, P. and Stranberg, E. (2005). Comparison between linear models and survival analysis for genetic evaluation of clinical mastitis in dairy cattle. Journal of Dairy Science, 88(2): 797-803.
CLSI, Clinical and Laboratory Standard Institute (2008). Performance standards for antimicrobial disk and dilution susceptibility tests for bacteria isolated from Animals. Pages 65-72. In: Approved standard M31-A3( $3^{\text {rd }}$ edn). Clinical and Laboratory Standards Institute, Wayne, PA.

Corbett, R. (2009). Minimizing the effects of immunosupression through management and nutrition. Proceedings of the $48^{\text {th }}$ Annual Meeting of the NMC, January 25-28, 2009, Charlotte, NC., pp:113-119.

DANMAP (2001). Use of antimicrobial agents and occurrence of antimicrobial resistance in bacteria from food animals, foods and humans in Denmark. The Danish Integrated Antimicrobial Resistance Monitoring and Research Programme, Copenhagen, Denmark.

Edward, M., Anna, K., Michal, K., Henryka, L. and Krystyna, K. (2002). Antimicrobial susceptibility of Staphylococci isolated from mastitic cows. Bulletin of Veterinary Institute in Pulawy, 289-294.

Fadlelmula, A., Al Dughaym, A.M., Mohamed, G.E., Al-Deib, M.K. and Al-Zubaidy, A.J. (2009). Bovine mastitis: Epidemiological, clinical and etiological study in a Saudi Arabian large dairy farm. Bulgarian Journal of Veterinary Medicine, 12(3): 199-206.

Galland, J.C., Hyatt, D.R., Crupper, S.S. and Acheson, D.W. (2001). Prevalence, antibiotic susceptibility, and diversity of Escherichia coli $\mathrm{O} 157: \mathrm{H} 7$ isolates from a longitudinal study of beef cattle feedlots. Applied Environmental Microbiology,4:1619-1627.

Gowri, B. (2010). Fatty infiltration of liver and its impact on fertility in bovines. Ph.D., Thesis submitted to Tamil Nadu Veterinary and Animal Sciences University, Chennai, India.

Green, M. and Bradely, A.(2004). Clinical Forum- Staphylococcus aureus mastitis in cattle UK. VET, 9: 4.

Juhasz-Kaszanyitzky, E., Janosi, S., Somogyi, P., Dan, A., Van der graaf-van Bloois, L., Van Duijkeren, E. and Wagenaar,J.A. (2007). MRSA transmission between cows and human. Emerging Infectious Diseases, 13: 630-632.

Karthikeyan, A. (2003). Clinicopathological and ultrasonographic studies in bovine mastitis. M.V.Sc., Thesis submitted to Tamilnadu Veterinary and Animal Sciences University, Chennai, India.

Kumar, R., Yadav, B.R. and Singh, R.S. (2010). Genetic Determinants of antibiotic resistance in Staphylococcus aureus isolates from milk of mastitic crossbred cattle. Current Microbiology, 60: 379-386.

Kumar, R., Yadav, B.R. and Singh, R.S. (2011). Antibiotic resistance and pathogenicity factors in Staphylococcus aureus isolated from mastitic Sahiwal cattle. Journal of Biological Science, 36: 175-188.

Lairintluanga, C., Ralte, E.I. and Hmarkunga (2003). Incidence of mastitis, bacteriology and antibiogram in dairy cattle in Aizawl, Mizoram. Indian Veterinary Journal, 80 (9):931- 932.

Lee, J.H. (2003). Methicillin(oxacillin)-resistant Staphylococcus aureus strains isolated from major food animals and their potential transmission to humans. Applied Environmental Microbiology, 69: 6489-6494.

Lehtolainen, T., Shwimmer, A., Shpigel, N.Y., Honkanen -Buzalski, T. and Pyorala, S. (2003). In vitro antimicrobial susceptibility of Escherichia coli isolates from clinical bovine mastitis in Finland and Israel. Journal of Dairy Science, 86: 3927-3932.

Loeffler, A. and Lloyd, D.H. (2010). Companion animals: a 
reservoir for methicillin-resistant Staphylococcus aureus in the community? Epidemiology of Infection, 138(5): 595-605.

Martineau, F., Picard, F.J., Lansac, N., Ménard,C., Roy, P.H., Ouellette, M. and Bergeron, M.G. (2000). Correlation between the resistance genotype determined by multiplex PCR assays and the antibiotic susceptibility patterns of Staphylococcus aureus and Staphylococcus epidermidis. Antimicrobial Agents Chemotheraphy, 44: 231-238.

Mohana Sundhari (2010). Diagnostic sensitivities of culture and polymerase chain reaction in bovine mastitis. M.V.Sc., Thesis submitted to Tamilnadu Veterinary and Animal Sciences University, Chennai, India.

Olde Riekerink, R.G.M., Barkema, H.W., Kelton, D.F. and Scholl, D.T.(2008). Incidence rate of clinical mastitis on Canadian dairy farms. Journal of Dairy Science, 91: 1366-1377.

Olsen, J.E., Christensen, H. and Aarestrup, F.M. (2006). Diversity and evolution of blaZ from Staphylococcus aureus and Coagulase negative Staphylococci. Journal of Antimicrobial Chemotheraphy, 57: 450-460.

Pitkala, A., Salmikivi, L., Bredbacka, P., Myllyniemi, A.L. and Koskinen, M.T.(2007). Comparison of tests for detection of beta-lactamase-producing Staphylococci. Journal of Clinical Microbiology, 45: 2031-2033.

Radostits, O.M., Blood, D.C. and Gay, G.C. (2008). Veterinary Medicine. A Textbook of the Diseases of cattle, sheep, pigs, goats and horses. $10^{\text {th }}$ Ed., Bailliare Tindall, London.

Sachin Kumar (2007). Comparative efficacy of ceftriaxone, enrofloxacin and amoxicillin-cloxacillin in bovine mastitis. M.V.Sc., Thesis submitted to Tamilnadu Veterinary and
Animal Sciences University, Chennai, India.

Sharma, N. and Maiti, S.K. (2010). Incidence, etiology and antibiogram of subclinical mastitis in cows in Durg, Chattisgarh. Indian Journal of Veterinary Research, 19: 45-54.

Sharma, N., Singh, N.K. and Bhadwal, M.S. (2011). Relationship of somatic cell count and mastitis: An overview. Asian - Australian Journal of Animal Science, 24: 429-438.

Sori, T., Hussein, J. and Bitew, M.(2011). Prevalence and susceptibility assay of Staphylococcus aureus isolated from bovine mastitis in dairy farms of Jimma town South west Ethiopia. Journal of Animal and Veterinary Advances, 10(6):745-749.

Turkyılmaz, S., Tekbıyık, S., Oryasin, E. and Bozdogan, B. (2010). Molecular epidemiology and antimicrobial resistance mechanisms of methicillin-resistant Staphylococcus aureus isolated from bovine milk. Zoonosis of Public Health, 57(3): 197-203.

Turutoglu, H., Hasoksuz, M., Ozturk, D., Yildirim, M. and Sagnak, S. (2009). Methicillin and aminoglycoside resistance in Staphylococcus aureus isolates from bovine mastitis and sequence analysis of their mecA genes. Veterinary Research Communication, 33(8): 945-956.

Waage, S.B., Bjorland, J., Caugant, A., Oppegaard, H., Tollersrud, T., Mork, T. and Aarestrup, F. (2002). Spread of Staphylococcus aureus resistant to penicillin and tetracycline within and between dairy herds. Epidemiology of infection, 129: 193- 202.

WHO (2000). WHO global principles for the containment of antimicrobial resistance in animals intended for food. WHO, Geneva, Switzerland. http://whqlibdoc.who.int/ hq/2000/WHO CDS CSR APH 2000.4.pdf. 